\title{
IJBF AN EMPIRICAL INVESTIGATION OF NEW BOND ISSUE YIELD SPREADS, DEFAULT RISK AND SPLIT RATINGS
}

\author{
Timothy S. Michael \\ University of Houston Clarke-Lake, United States \\ of America
}

\begin{abstract}
This paper attempts to explain the yield spreads charged to new corporate debt issues by comparing the initial yields of a set of 3,287 securities issued over eleven years in the US. We use the measure of constant maturity Treasury rates on the day of issue against the Moody's Aaa Corporate Bond index for the week prior to the issue, and the yield on a daily index of long-term Treasury securities on the issue date. The influences of credit ratings and disagreement between rating agencies as reflected in split ratings and the interactions between these characteristics are measured. The contributions of sinking fund provisions, call or refunding status, overseas issue and contractual security arrangements are evaluated separately. The results support the view that the higher yields are observed when ratings of agencies differ and that factors associated with the issues also are significant drivers of the yield difference.
\end{abstract}

Key words: Yield spreads, Split ratings, Bond index, Credit rating effect, Terms of debt issues

JEL Classification: E43, G12

\section{Introduction}

The influences of credit ratings and disagreement between rating agencies and the interactions between these characteristics are issues that are addressed in this paper. We include in this paper new findings on the contributions of sinking fund provisions, call status, overseas issues and contractual security arrangements. The yield spreads of debt issues contain important information for investment analysts to judge the level of risk of an issue. Therefore, an analysis of the yield spreads to identify the factors in a debt issue is expected to add to our understanding of risk of an issue thus aiding analysts in their investment evaluation. 
The model tested in this paper was most influenced by a prior work on split bond ratings and security yields by Billingsley, Lamy, Marr, and Thompson (1985) (BLMT). In their model, BLMT measure the yield off-Treasury (YOT) for new securities, defined as issuing yield less Moody's index of long-term government bonds on the issue date. To explain this spread measure, they used the average daily interest rate (level) on Moody's long-term Treasury bond index, an absolute deviation measure of volatility in interest rates for the ten days prior to the issue date, a quality spread of the average yield on long-term corporate bonds over the Treasury index rate on the issue date, the natural log of the issue size, the term to maturity of the issue, and the minimum number of years until first call. They also include dummy variables for four Moody's rating classes, the existence of a sinking fund provision, and four separate split rating categories for single interclass splits. ${ }^{1}$

The rest of the paper is organized as follows. Section 2 is a review of the literature relating to the yield spreads at the time of issue relating to split ratings by two rating companies. In section 3 we present the research design of this study, and the results are discussed in section 4 . The paper ends with comments in section 5.

\section{Brief Review of Related Literature}

For a sample of 258 new industrial bonds issued between 1977 and 1983, BLMT find significant relationships between YOT and an overall quality spread, the level of interest rates, term to maturity, call term, and all four ratings classes (the omitted class, as represented by the intercept term, was not significant). In addition, the coefficients for the split categories Aaa/Aa, Aa/A and A/Ba are also significantly different from zero, and inversely related to the YOT. Using a standard F-test for a subset of coefficients, BLMT show that the coefficients on the class dummies are significantly different in all but the Aaa versus Aa case. Their results indicate that split rating coefficients are significantly related to the higher rating class (with the exception of the Aaa/Aa split), suggesting that the market may weigh bad information more heavily when assigning initial yields to an issue which has caused a difference in rating agency opinion. In other words, there is a significant difference in yields when (for their sample) the Moody's rating of the issue is higher than that given by Standard and Poor's.

The potential impact of the BLMT (1985) results suffers from a lack of degrees of freedom. As pointed out by Perry, Liu and Evans (1988), of the 258 issues in the BLMT study, only 33 have a split rating, making the fine distinctions found by BLMT little suspect, or at least in need of confirmation by a larger sample. Perry, Liu and Evans (1988) confirm the relationship between splits, yields, and the higher ratings class for a larger sample, again using each

\footnotetext{
${ }^{1}$ An example of an interclass split would be an issue rated Aaa by Moody's and AA by Standard and Poors. No provision was made to measure the splits across more than just broad classes. Revised categories, which distinguish between three different intraclass ratings, were not used in the BLMT study.
} 
issue's Moody rating as a base. Liu and Moore (1987) reaffirm the these prior relationships, but show that the phenomenon is not significantly different for Moody's versus Standard and Poor's, suggesting that a large premium is demanded from any issue which is rated lower than the rating on a benchmark portfolio of equally-rated bonds.

There is also a stream of literature which explores the relationship between security ratings, default risk and split ratings, and these studies question the ability of credit ratings to capture the market's full assessment of default risk at different points in a security's life. This line of research is characterized by the studies of Ederington (1986), Ederington, Yawitz and Roberts (1987), and Reiter and Ziebart (1991). ${ }^{2}$ Evidence from this body of works suggests that ratings may become "stale" for some firms since rating agencies may not revise a firm's credit ratings at regular or frequent intervals. As a response to concerns about this issue in the current study, it should be pointed out that the inaccuracy of ratings in capturing the default risk of a particular security should be small for new issues relative to seasoned securities. Most prior studies designed to evaluate default risk proxies have used samples of outstanding bonds.

The default risk literature provides evidence that credit rating categories are significantly related to new issue yields. For example, Ederington, Yawitz, and Roberts (1987) show that ratings are significant and capture most of the variation in yields, even when combined with firm-specific accounting measures. The credit rating assigned a new issue is likely to be the most complete timely measure of default risk available to the majority of bond investors.

Another question from default risk research is whether yields are determined by credit ratings or credit ratings are determined by issue yields. Reiter and Ziebart (1991), Kao and Wu (1994) and Liu and Thakor (1984) all recognize the simultaneity of bond rating and price determination. This problem is not addressed in the current paper, other than to suggest that the direction of causality for new issues is probably more from ratings to yields. This relationship should be clearest for a new security given the nature and timing of the issuing process, which also impacts new issue liquidity.

The direct effect of illiquidity on seasoned corporate bond prices is well documented. Zivney, Bertin and Torabzadeh (1993) review the impact of infrequent trading on the availability and quality of high-yield bond price data. For the present study, confining the sample to yields on new issues is partly an attempt to minimize liquidity differences between a particular new issue, Treasury securities, and the bonds included in Moody's Aaa Corporate Bond index. If systematic liquidity effects exist, they should be smallest at issue time. This assertion acknowledges the discretionary nature of most debt issues - investment bankers advise firms (or savvy firms know) when to issue based

\footnotetext{
2 Kaplan and Urwitz (1979) show that studies attempting to explain bond ratings using standard OLS models and a categorical dependent variable for rating class are flawed. As a result of their original study, ordered probit models of ratings have been developed over the past decade. These newer models are used in most of the recent research on default risk.
} 
on the banker's ability to sell at some target price. The final data used here are made up of only those securities for which a substantial amount of information is present at the time of issue; these are likely to be the most actively traded securities once they are issued.

The models tested in this paper are also guided by the sinking fund model of Kidwell, Marr, and Ogden (1989), which uses a standard YOT equation with interaction terms to measure the potential slope differences for sinking fund issues as they relate to the overall level of interest rates and an ordered probit model measure of default risk. The sample included 192 new utility issues during 1977 and 1982 period. Both of these interactions are highly significant in that study, but a simple dummy variable for sinking fund presence was only significant at the 0.10 acceptance level. A similar model explaining yield level rather than a quality spread is estimated by Kidwell, Marr and Thompson (1984). Both studies included some measure of term to maturity, the overall level of interest rates, and some recognition of the call provision associated with the issue. These variables added explanatory power in each case. Other related models are the yield models of Sorensen (1981 and 1979). Hsueh and Chandy (1989) developed a similar model for the net issuing cost of insured and uninsured municipal bonds.

\section{Research Design}

A basic model of the quoted interest rate on a debt security is given by Brigham and Gapenski (1994, pg. 103):

$$
\mathrm{Y}_{\mathrm{i}}=\mathrm{k}^{*}+\mathrm{IP}_{\mathrm{i}}+\mathrm{LP}_{\mathrm{i}}+\mathrm{MRP}_{\mathrm{i}}
$$

where, $\mathrm{Y}$ is the quoted rate on security $i, \mathrm{k}^{*}$ is the real risk-free rate of interest, IP is an inflation premium, DRP is a default risk premium, LP is a premium for liquidity risk, and MRP is a premium for maturity risk.

At any point in a debt security's life, it should be possible to decompose its yield into subsets resembling those in the quoted rate expression. Similarly, the simplest way to measure any set of the right-hand-side premia is to subtract from both sides the yield on a security which is similar to the measured security in all but the targeted set of characteristics. A Treasury yield, for example, contains the real rate, inflation expectations, and if it is of the same term as the measured bond, the same maturity risk premium, leaving default and liquidity risk to explain the yield differential. ${ }^{3}$ Liquidity effects can be reduced by using new issue information, so this example would end up being primarily a model of default risk.

\footnotetext{
3 Kidwell, Marr and Ogden (1989) indicate that new issue yields should not reflect any differences in price due to different coupon rates on the compared securities because most issues are priced close to par at issue. To make sure that this kind of influence was removed from the sample, original-issue-discount bonds were dropped, as described in Section 4.
} 
For the set of corporate debt securities which have been rated by Moody's and Standard \& Poor's, the default risk component of a security's yield can be broken into two parts. As a base, the spread between an index of Aaa corporate bonds and the constant maturity Treasury rate for a particular term represents the minimum default spread charged in the market on a given issuing day. The default premium on any new security should be greater than or equal to this Aaa quality spread on the day the reissuing price is set, which may be up to a week prior to issue. ${ }^{4}$ In other words, the difference between the measured new issue yield and a Treasury rate will contain or at least be a function of the default premium on an index of Aaa bonds on the issue date. The difference between the premium paid by a Aaa bond (or index) and the new issue will contain premia to pay for all other sources of default risk. In reality, and as measured here, this difference will contain components of liquidity risk and perhaps maturity risk as well.

The base model evaluated in this paper is of the form:

$$
\begin{aligned}
& \mathrm{Y}_{\mathrm{i}, \mathrm{d}, \mathrm{T}}=\mathrm{T}_{\mathrm{d}, \mathrm{T}}+\left[(\text { Aaa index })_{\mathrm{d}}-\mathrm{T}_{\mathrm{d}, \mathrm{T}}\right]+\mathrm{DRP}_{\mathrm{i}}+\text { other premia } \\
& \text { YOT }_{\mathrm{i}}=\left(\mathrm{Y}_{\mathrm{i}, \mathrm{d}, \mathrm{T}}-\mathrm{T}_{\mathrm{d}, \mathrm{T}}\right)=\left[(\text { Aaa index })_{\mathrm{d}}-\mathrm{T}_{\mathrm{d}, \mathrm{T}}\right]+\mathrm{DRP}_{\mathrm{i}}+\text { other premia }
\end{aligned}
$$

Where, $\mathrm{Y}_{\mathrm{i}, \mathrm{d}, \mathrm{T}}$ is the observed yield on new issue $i$ on issue data $d$ with a term to maturity of $T$ years. $\mathrm{T}_{\mathrm{d}, \mathrm{T}}$ is the day $d$ observed yield on a Treasury security with a term to maturity of $T$ years. ${ }^{5}$ The Aaa index measure is the last weekly yield on Moody's Aaa Corporate Bond index for the week up to and including the issue date, and $\mathrm{DRP}_{\mathrm{i}}$ is a unique default risk premium for the new issue.

The general category "other premia" may contain a great deal of pricing information. The analysis in this paper limits the investigation of this category to residual term effects, the effect of gross issue size, the yield premium demanded for issuing abroad ("Euro" securities), the level of volatility in an overall quality spread for corporate bond yields for some period prior to issue, and the effect of having a call or refunding provision. Differential default risk is measured as outlined above, using a quality spread for corporate yields, defined as Moody's Aaa Corporate Bond index less the constant maturity Treasury yield corresponding to the exact term to maturity of the measured issue. ${ }^{6}$ Default

\footnotetext{
4 To the extent that the Aaa bond index is a noisy measure of the current yield paid by high quality credits, this model is flawed. The data series used here -- weekly values of Moody's Aaa Corporate Bond index -- is the most accurate available from public electronic sources. Better precision could be obtained by matching each new issue with an actual Aaa corporate bond of the same term on the issue date, but this would introduce other factors into the model.

5 I chose to subtract Treasuries from issue yield in order to reduce measurement error and collinearity influences on the right-hand-side of the model; measurement error in the YOT affects the size of the error term.

${ }^{6}$ Moody's Aaa Corporate Bond index for one and two weeks prior to the issue date were also tested in relation to each of the models developed. The results reported were the most significant.
} 
risk is also measured by categorical variables for six separate Moody's rating classes: Aaa, Aa, A, Baa, Ba, and B. In addition, dummy variables for secured issues, the existence of sinking fund provisions, and disagreement between credit rating firms (split ratings) are included. Following an initial specification and estimation, separate categories indicating the magnitude (1 through 3 revised rating subclasses) and direction (positive or negative) of rating splits are introduced and tested. Finally, a respecified model adds interactions between the rating classes and the split magnitude and direction terms.

The issue's YOT is a spread over some base rate, which may or may not be known or well-proxied by an observable rate. The right side of this equation may contain many items related to the issue that are not found in the base rate or its proxy, yet there is no sound theoretical reason that an interest rate level component should contribute to the yield spread on the left. Models which use full interest rates to explain yield spread are assuming a great deal about the timeseries behavior of default risk. ${ }^{7}$ As another consideration, an interest rate level may be highly collinear with other explanatory variables. At least two existing studies (Perry, Liu and Evans (1988) and Liu and Moore (1987)) avoid this question and measure the impact of ratings splits on yields spreads in directly. The results of both of these studies are robust to this criticism.

This study was originally designed to take advantage of data recently made available by the Capital Markets Division of the Federal Reserve Board of Governors. ${ }^{8}$ The full data base is composed of 10,286 new corporate debt securities of varying characteristics issued between 1982 and 1993, with information originally taken from The Wall Street Journal, S\&P Credit Week, Moody's Bond Survey, Investment Dealer's Digest, International Financing Review, and Bloomberg Business News (Guedes and Opler (1995)). ${ }^{9}$ Though incomplete for some items, the data set includes for most issues the gross amount, initial yield, coupon rate, issue date, maturity date, Standard \& Poor's rating, Moody's rating, date (year) of first call, first refunding date, and the first sinking fund payment date (year). In addition, there are several classification items provided which describe some of the relevant characteristics of each issue, such as whether it is convertible, an original-issue-discount (OID) security, or was sold in relation to a merger or swap.

Using all of these indicators combined, it was possible to reduce the initial set to a group of 4,647 debt securities with issue dates between January 3, 1983

\footnotetext{
${ }^{7}$ Given the obvious popularity of using rates levels to explain rate spreads, there may be extremely valid theoretical reasons for including the absolute magnitude of interest rates in models. It stills seems counterintuitive to the author.

8 The complete data set in raw form is available in both comma-separated-value (CSV) and Excel formats from Dr. Tim Opler's World-Wide Web page at http://www.cob.ohiostate.edu/dept/fin/osudata.htm.

${ }^{9}$ Guedes and Opler (1995) report 10,287 records in the original file. For this paper, the data file was read into DBFAST 2.0 as text and number fields and converted to a Dbase III format data matrix. The original number of observations in the data set when read was 10,286 .
} 
and June 30, 1993. Approximately 1,300 issues were dropped for not having a listed maturity date. Issues were kept if they were rated at issue by both Moody's and Standard and Poor's (approximately 6,300 issues). Securities without an entry for either rating or with a UN or NR listing were deleted. Issues without yield or gross issue size numbers were also removed. From the remaining securities, the following major categories were deleted: convertibles, warrant bonds, unit issues, foreign bonds, guaranteed or government-backed issues, private placements, OID issues, participation certificates, RESETs, "Poison put" issues, Merrill-Lynch LYONS, variable or adjustable rate securities, merger related securities, and securities with specific event risk covenants.

The remaining observations should include only short, medium and longterm straight debt, notes, mortgage bonds (and other secured issues) meeting the above criteria. The original data does not provide any way to divide the individual issuers into their appropriate industries. ${ }^{10}$ For this reason, the data set contains issues by utility, industrial and financial firms. An anticipated extension of this paper will be to correct the data for obvious industry effects by removing all but industrial firms from the sample. This data also include multiple issues by the same firm if they meet the qualifications listed.

Each valid observation was subsequently matched to a daily Treasury yield by term and issue date. Information for comparable Treasury securities was obtained from Federal Reserve Statistical Release H.15. ${ }^{11}$ For each issue date, this source provides a daily yield on an index of government bonds with maturities between ten and thirty years, daily constant maturity (CM) Treasury yields for 1, 2, 3, 5, 7, 10 and 30 year maturities, and most daily 20-year CM rates between 1982 and 1987. After matching, 3,293 securities had issue dates and terms corresponding to the available Treasury yield data. These matching rates were subtracted from issue yield to obtain YSPRCMA, the actual yield spread on the date of issue for each security. These were then matched to weekly observations (daily averages) of Moody's Aaa Corporate Bond index in order to calculate the explaining spread variable CMQSYLD, which is the Aaa index yield minus the actual comparable constant maturity rate for each issue on the issue date. Table 1 gives the distribution by year and term for the final sample of new securities. ${ }^{12}$

10 Guedes and Opler (1995) report that out of 10,287 observations, they were able to match 7,369 to Standard and Poors COMPUSTAT (presumably by CUSIP number, which is included in the data set). This would allow for industry identification. In addition, they report that their models often used fewer than 7,369 observations due to missing data in the COMPUSTAT files.

11 Weekly and daily numbers for key interest rates are available in a variety of files and formats from the Federal Reserve at either its Chicago or St. Louis district banks. The electronic resources of the entire Federal Reserve System can be accessed in the FRED data base, located at http://www.stls.frb.org.

${ }^{12}$ Note that the totals in each table are adjusted for the removal of outliers as discussed in Section V., below. 
Table 1: Annual security issues by term to maturity

For the sample of 3,285 new corporate debt securities issued between January 3, 1983 and June 30,1993, with known maturity dates and yields which could be matched by term to maturity with a constant maturity Treasury rate on the date of issue. This sample does not include any convertible, original-issue-discount, floating rate or foreign issues. Note: 20-year constant maturity Treasury rates are only available prior to 1987 and after June 1993. Term was measured as the number of years from the issue date until the listed maturity date (when available) or as the number of years between the maturity year and the year of issue.

\begin{tabular}{|c|c|c|c|c|c|c|c|c|c|c|}
\hline \multirow[b]{2}{*}{ Year } & \multicolumn{9}{|c|}{$\begin{array}{l}\text { Term to Maturity } \\
\quad \text { (in years) }\end{array}$} & \multirow[b]{2}{*}{ Avg. } \\
\hline & 1 & 2 & 3 & 5 & 7 & 10 & 20 & 30 & Total & \\
\hline 1983 & & 1 & 2 & 4 & 7 & 39 & & 61 & 127 & 20.34 \\
\hline 1984 & & 2 & 7 & 10 & 11 & 51 & & 25 & 116 & 13.89 \\
\hline 1985 & 1 & 1 & 6 & 16 & 32 & 111 & & 73 & 251 & 15.32 \\
\hline 1986 & & & 10 & 38 & 52 & 184 & 13 & 167 & 472 & 16.64 \\
\hline 1987 & 1 & 2 & 3 & 38 & 41 & 111 & 10 & 91 & 302 & 14.49 \\
\hline 1988 & 2 & 3 & 8 & 47 & 35 & 111 & 11 & 59 & 265 & 12.80 \\
\hline 1989 & 25 & 7 & 1 & 12 & 16 & 85 & 21 & 64 & 210 & 14.21 \\
\hline 1990 & 6 & 9 & 12 & 22 & 22 & 50 & & 48 & 169 & 13.39 \\
\hline 1991 & 7 & 8 & 23 & 44 & 48 & 85 & & 108 & 323 & 14.67 \\
\hline 1992 & 9 & 14 & 39 & 93 & 127 & 222 & & 123 & 627 & 11.83 \\
\hline 1993 & 2 & 4 & 21 & 52 & 78 & 157 & & 111 & 425 & 13.59 \\
\hline Totals: & 53 & 51 & 147 & 376 & 467 & 1,206 & 55 & 930 & 3,287 & 14.65 \\
\hline
\end{tabular}

Grand Total: 3,287 issues

Table 2 presents descriptive statistics for the important measured and calculated variables YIELD, CMYLD, YOT, CMQSYLD and GROSS for each year of sample data. These statistics indicate the means, variability and the range of values by year. The means of the four variables indicate that the measures are in line with previously reported figures, although these measures are from a very large sample used in this study. The data set contains issue with maturities of 1 to 30 years (see the columns) across 11 years as rated by the rating agencies. There is a total of 3,287 observations in this study.

Table 3 shows the breakdown of the four non-rating categories (EURO, SECDUM, CRFDUM and SFDUM) and the SPLIT dummy variable for each year. The categories in Table 3 are not mutually exclusive. 
Table 2: Annual descriptive statistics for selected data series

For the sample of 3,285 new corporate debt securities issued between January 3, 1983 and June 30, 1993, with known maturity dates and yields which could be matched by term to maturity with a constant maturity Treasury rate on the date of issue. This sample does not include any convertible, original-issue-discount, floating rate or foreign issues. Year is the year of issue; $\mathrm{N}$ is the number of observations in that year; Yield is the measured yield-atissue of the new security, in percent; CMYLD is the constant maturity Treasury rate for the same term as the new issue on the issuing date; YOT is (Yield - CMYLD); CMQSYLD is the average yield on Moody's Aaa Corporate Bond Index (weekly) for the issue date minus CMYLD; GROSS is the total size of the security issue in millions of dollars.

\begin{tabular}{|c|c|c|c|c|c|c|c|}
\hline \multirow[b]{2}{*}{ Year } & \multirow[b]{2}{*}{$\mathbf{N}$} & & \multicolumn{5}{|c|}{ Variable Name } \\
\hline & & & $\begin{array}{c}\text { Yield } \\
(\%)\end{array}$ & $\begin{array}{c}\text { CMYLD } \\
(\%)\end{array}$ & $\begin{array}{l}\text { YOT } \\
(\%)\end{array}$ & $\begin{array}{c}\text { CMQSYLD } \\
(\%)\end{array}$ & $\begin{array}{c}\text { GROSS } \\
(\$ M)\end{array}$ \\
\hline \multirow[t]{4}{*}{1983} & 125 & Mean & 12.08 & 10.84 & 1.23 & 1.036 & 89.84 \\
\hline & & St. Dev. & 1.2611 & 0.6135 & 0.9697 & 0.3876 & 45.10 \\
\hline & & Min. & 7.00 & 9.26 & -3.78 & 0.42 & 15 \\
\hline & & Max. & 15.50 & 12.15 & 3.88 & 2.51 & 250 \\
\hline \multirow[t]{4}{*}{1984} & 116 & Mean & 13.60 & 12.24 & 1.36 & 0.48 & 90.85 \\
\hline & & St. Dev. & 1.4326 & 0.7438 & 1.1695 & 0.4701 & 56.60 \\
\hline & & Min. & 10.30 & 10.29 & -0.45 & -0.57 & 8 \\
\hline & & Max. & 17.61 & 13.99 & 5.14 & 1.92 & 300 \\
\hline \multirow[t]{4}{*}{1985} & 251 & Mean & 11.53 & 10.44 & 1.09 & 0.86 & 103.61 \\
\hline & & St. Dev. & 1.5613 & 0.7228 & 1.4404 & 0.3554 & 65.78 \\
\hline & & Min. & 6.72 & 7.94 & -3.55 & 0.23 & 3 \\
\hline & & Max. & 16.03 & 12.00 & 6.54 & 3.17 & 500 \\
\hline \multirow[t]{4}{*}{1986} & 472 & Mean & 9.37 & 7.55 & 1.82 & 1.45 & 120.02 \\
\hline & & St. Dev. & 1.5681 & 0.6167 & 1.5554 & 0.3192 & 72.43 \\
\hline & & Min. & 6.50 & 6.42 & -0.98 & 0.30 & 8 \\
\hline & & Max. & 14.31 & 9.67 & 7.21 & 2.35 & 440 \\
\hline \multirow[t]{4}{*}{1987} & 302 & Mean & 9.86 & 8.11 & 1.75 & 1.09 & 124.07 \\
\hline & & St. Dev. & 1.7698 & 0.7549 & 1.5629 & 0.4179 & 90.76 \\
\hline & & Min. & 6.07 & 6.37 & -2.48 & 0.34 & 2 \\
\hline & & Max. & 16.94 & 9.96 & 10.57 & 2.92 & 900 \\
\hline \multirow[t]{4}{*}{1988} & 265 & Mean & 10.41 & 8.69 & 1.72 & 1.065 & 133.07 \\
\hline & & St. Dev. & 1.9150 & 0.3744 & 1.7982 & 0.3486 & 75.21 \\
\hline & & Min. & 5.14 & 7.59 & -3.86 & 0.36 & 3 \\
\hline & & Max. & 17.51 & 9.40 & 8.43 & 2.17 & 500 \\
\hline \multirow[t]{4}{*}{1989} & 210 & Mean & 10.30 & 8.51 & 1.78 & 0.77 & 152.47 \\
\hline & & St. Dev. & 1.8420 & 0.6298 & 1.7619 & 0.3175 & 102.09 \\
\hline & & Min. & 5.15 & 7.53 & -3.50 & -0.06 & 3 \\
\hline & & Max. & 15.50 & 9.85 & 7.09 & 1.38 & 750 \\
\hline \multirow[t]{4}{*}{1990} & 169 & Mean & 9.56 & 8.42 & 1.14 & 0.92 & 166.91 \\
\hline & & St. Dev. & 0.7068 & 0.3042 & 0.6143 & 0.2784 & 117.93 \\
\hline & & Min. & 7.75 & 7.47 & 0.07 & 0.37 & 15 \\
\hline & & Max. & 14.60 & 9.08 & 6.29 & 1.78 & 750 \\
\hline \multirow[t]{4}{*}{1991} & 323 & Mean & 8.84 & 7.69 & 1.14 & 1.07 & 173.95 \\
\hline & & St. Dev. & 1.0969 & 0.6119 & 0.8578 & 0.5417 & 132.24 \\
\hline & & Min. & 5.05 & 4.98 & -1.37 & 0.44 & 4 \\
\hline & & Max. & 13.50 & 8.53 & 6.39 & 3.57 & 1,500 \\
\hline \multirow[t]{4}{*}{1992} & 627 & Mean & 8.09 & 6.68 & 1.41 & 1.45 & 151.60 \\
\hline & & St. Dev. & 1.8244 & 0.8829 & 1.4785 & 0.8226 & 114.65 \\
\hline & & Min. & 3.45 & 3.36 & -0.46 & 0.22 & 1 \\
\hline & & Max. & 13.33 & 8.06 & 6.72 & 4.58 & 900 \\
\hline \multirow[t]{4}{*}{1993} & 425 & Mean & 7.35 & 6.05 & 1.29 & 1.55 & 158.96 \\
\hline & & St. Dev. & 1.6289 & 0.7436 & 1.4355 & 0.7071 & 132.13 \\
\hline & & Min. & 3.48 & 3.28 & -0.24 & 0.39 & 1 \\
\hline & & Max. & 13.00 & 7.48 & 7.47 & 4.33 & 1,250 \\
\hline
\end{tabular}


Table 3: Annual security issues by type of issues

For the sample of 3,285 new corporate debt securities issued between January 3, 1983 and June 30,1993, with known maturity dates and yields which could be matched by term to maturity with a constant maturity Treasury rate on the date of issue. This sample does not include any convertible, original-issue-discount, floating rate or foreign issues. Note: categories here are not mutually exclusive. Year is the year of issue; $\mathrm{N}$ is the number of observations in that year; EURO is a dummy variable indicating whether the security was issued in a foreign market by a domestic firm; SFDUM is a dummy variable which is 0 if a sinking fund provision exists for the issue; SECDUM is a dummy variable indicating that the issue is secured (mortgage, lease or equipment trust related); CRFDUM is a dummy variable which is 1 if the call or refunding date is included in the original issue announcement; SPLIT is a dummy variable which is zero if the issue's Moody's rating is equivalent to the rating assigned by Standard and Poors.

\begin{tabular}{ccccccc}
\hline & & \multicolumn{5}{c}{ Variable Name } \\
\cline { 3 - 7 } Year & $\mathbf{N}$ & EURO & SFDUM & SECDUM & CRFDUM & SPLIT \\
\hline 1983 & 127 & 6 & 15 & 64 & 87 & 73 \\
1984 & 116 & 1 & 12 & 44 & 62 & 74 \\
1985 & 251 & 33 & 23 & 61 & 159 & 142 \\
1986 & 472 & 29 & 44 & 151 & 255 & 291 \\
1987 & 302 & 10 & 46 & 81 & 149 & 176 \\
1988 & 265 & 17 & 28 & 56 & 135 & 151 \\
1989 & 210 & 7 & 20 & 54 & 80 & 106 \\
1990 & 169 & 1 & 7 & 47 & 40 & 76 \\
1991 & 323 & 14 & 5 & 61 & 49 & 144 \\
1992 & 627 & 16 & 11 & 211 & 144 & 315 \\
1993 & 425 & 4 & 4 & 151 & 123 & 230 \\
& & & & & & \\
Totals & 3,287 & 138 & 215 & 981 & 1,283 & 1,778 \\
\hline \hline
\end{tabular}

\section{Findings and Discussion}

\section{A) A Simple Model}

The second column of Table 4 shows the results of an initial regression model (Model 1A) fit to the full comparable data set. ${ }^{13}$ The maturity-matched

13 The techniques and specifications in this section were originally applied to the full 4,676 observations as well as those with directly comparable maturity matches $(3,293$ observations with outliers). For the full data set, YOT was calculated as the issue yield minus the daily yield on a long-term Treasury index; the RHS spread variable used was the yield on Moody's Aaa Corporate Bond index less the daily Treasury bond index yield. These regressions never produced a significant coefficient for the spread variable, even when all different lagged values of spread and volatility (standard deviation or meanabsolute-deviation) were estimated in turn. A full interest rate level measure on the RHS didn't improve any of these models over the specifications reported, either. 
spread measure, issue term, volatility (measured by mean absolute deviation) and four of five bond class coefficients are significant at the 0.01 acceptance level, with the remaining rating class (Aaa) dummy significant at the 0.05 levels. The size factor and the call/refund dummy are significant at the 0.10 levels. The intercept, which corresponds to the A rating class, is not different from zero. An F-test for overall significance rejects the null hypothesis at the 0.01 level. ${ }^{14}$

Initial results (not presented) were sensitive to the choice of the omitted rating class. Early specifications of the model using Aaa as the omitted class were designed to make interpretation of the difference between lower yields and the quality spread variable clearer, but these models showed high levels of multicollinearity between the size variable and several bond classes. ${ }^{15}$ When the omitted class was changed to $\mathrm{B}$, these problems disappeared, but several of the other regressors lost significance. Finally, the A class was chosen due to its large number of observations relative to the other classes and the balanced results it provided. ${ }^{16}$

In addition to the original specification used in Model 1A, the model was estimated for measured values of the quality spread and volatility variables observed one and two weeks prior to the issue date (these results are not presented). These models were no more significant or intuitive than the base case. The model was also tested using one and two-week lagged values of the prior 26-week standard deviations in place of the mean-absolute-deviation term; there was a slight decrease in significance for several regressors, and the overall explanatory power dropped. As shown by its retention in Model 1A, the TERM variable performs better than its natural log, although GROSS does not.

After adjusting the omitted class, the regressor, variance inflation factors, in Model 1A dropped to near one. ${ }^{17}$ In addition, the model's condition number,

\footnotetext{
${ }_{14}$ Models 1B, 2 and 3 are also significant at the $1 \%$ level.

15 Aaa was originally made the omitted class to avoid problems with the lack of negative splits associated with this class. A Standard and Poors security rating can never be higher than Aaa, so there would never be any observations of an interaction term between the class Aaa and the split categories which represent one subclass rating (e.g., Aa+ versus Aa) higher than the current class, two classes higher, and three classes higher.

16 This specification problem suggests that the overall relationship between default risk and quality spreads not likely to be linear. Even so, the relationship between individual rating classes and yield spreads may still be linear.

17 The VIF option in SAS PROC REG produces variance inflation factors, which are the inverse of the tolerance for each regressor. Freund and Littell (1991) note that these should be below the reciprocal of one minus the r-squared for the overall regression, since the VIF is reciprocal of one minus the r-squared for a regression of each regressor on the others; a high VIF indicates that the other independent variables are more closely related to the variable in question than to the dependent variable. For this initial regression, the suggested threshhold value is 3.352. Freund and Littell also note that other authors consider 10 to be an acceptable threshhold value.
} 
formerly above forty, dropped to below $25 .{ }^{18}$ Multicollinearity, obviously present in each of these models, was not necessarily harmful to the results.

The initial model was tested for the presence of influencial outlier values. Eight observations (out of 3,293) were found to be extreme and were dropped from the data set used to estimate the remaining regressions. Dropping these data points increased the fit of the overall regression and increased the significance of most of the coefficients. This is Model 1B in Table IV. In addition, the coefficient on EURO was found to be negative and significantly related to the YOT at the 0.05 level. ${ }^{19}$ These eliminations improved the fit of Models 2 and 3 as well.

The error variances were examined for heteroskedasticity using GoldfeldQuandt tests as described in Kennedy (1992) and Pindyk and Rubenfeld (1981). Tests were performed for CMQSYLD, TERM and LNGROSS as suspected related regressors; only CMQSYLD marginally rejected the null. A weighted least squares performed to correct this relationship only increased the GoldfeldQuandt test statistic, which suggests that there may be a relevant variable left out of the model. ${ }^{20}$

The most likely omitted variable is one which conveys information about the general level of interest rates. As noted above, most prior models have incorporated some value of contemporaneous interest rates to increase their explanatory power. A measure of the Moody's Aaa Corporate Bond index yield minus the rate on a daily index of long-term government bonds was added as a regressor; the Aaa Corporate Bond index yield and the Treasury bond index yield were each added separately in turn. None of these changes lower the level

18 The condition number is reported in SAS using the COLLIN option with PROC REG. This number is given along with the variance proportion for each independent variable. Freund \& Littell (1991) suggest that a condition number greater than thirty may indicate a problem with multicollinearity. A high condition number for a given eigenvalue combined with variance proportions of over 0.5 for any regressors indicates that these regressors may cause collinearity problems. In the initial screen of Model 1A (with outliers), the model was tested without the LNGROSS term to attempt to correct for a multicollinearity problem according to a high variance proportion and a large condition number. No significant changes resulted.

19 Diagnostic values of the hat matrix, RSTUDENT, COVRATIO, DFFITS, and DFBETAS were generated using the INFLUENCE model option available in SAS PROC REG. These were output to a separate data set and tested for cutoff values as described in SAS/STAT User's Guide, Version 6 (1989) using summary and screening procedures, for fifteen parameters estimated (p) and the number of observations [n]. DFBETAS for this model were inspected individually. In all cases, the deleted observations had RSTUDENT values greater than two in absolute value and $\mathrm{H}$ values greater than $[2 * \mathrm{p} / \mathrm{n}]$. None of the observations had extreme values of DFBETAS, COVRATIO, or DFFITS.

${ }^{20}$ The reweighting in this case consisted of dividing all observations by CMQSYLD, as suggested by Pindyk and Rubenfeld (1981). 
of heteroskedasticity in the model, nor does the addition of the actual constant maturity Treasury yield on an issue-by-issue basis (CMYLD). ${ }^{21} 22$

For Model 1B, F-tests are used to evaluate the joint impact of the set of rating class coefficients; these are significantly different from zero as a group (including the intercept) at the 0.01 level. The coefficient for the Aaa class is not significantly different from that of the Aa class, and the Aa class is not different from the A class (intercept). The first of these results confirms the findings of BLMT (1985) regarding the explanatory power of different rating class categories. The remaining adjacent class coefficients are different from each other at the $1 \%$ level, consistent with prior research. These results suggest that the default risk distinction is not as obvious between higher rating classes than between ratings overall.

The coefficients for CRFDUM (the existence of call or refunding provisions) and EURO (overseas issue) are both different from zero at the 5\% level in Model 1B. The coefficients for SECDUM (secured issues) and SFDUM (sinking fund) are not significantly related to yield spreads in this sample. These four relationships hold for each of the models discussed below as well.

\section{B) More Complex Specifications}

From Table 4, it is clear that the ratings categories explain a great deal of the variance in an issue's YOT, but the SPLIT designator has no statistical influence on the model results. In Model 2, the split category variable is replaced by six dummy variables which indicate the direction and the magnitude of the split; those securities with equal Moody's and Standard and Poors ratings make up the omitted class. ${ }^{23}$ These results are shown in column four of Table 4.

The six split categories represent one, two or three numerical values away from the Moody's rating in either the positive $(\mathrm{P})$ or negative $(\mathrm{N})$ direction. All of the positive split coeffients are individually different from zero at the 0.05 level and directly related to YOT, indicating a direct relationship between a higher Moody's rating and an issue's yield spread in the subclass categories

${ }^{21}$ Both Breusch-Pagan and White tests, as described by Kennedy (1992), were used to confirmed the general nature of the unequal error variance in the original model. Another weighted least squares procedure, also from Kennedy, was estimated by weighting the observations by the square root of the estimated error variance from the original regression to produce GLS estimators. A Goldfeld-Quandt test on this regression also indicated significant heteroskedasticity at the prior levels. For this reason, the remaining analysis and extension was done on the original equation and additions to it; an extension of this paper would be to re-estimate these models using an appropriate specialized panel data approach.

22 Durbin-Watson statistics were tested to assess the level of autocorrelation in the error terms. These are close to 2 for all models tested, and the first-order autocorrelations calculated for residuals are generally below 0.13 . For the four models presented, the first-order rhos are less than 0.10 .

${ }^{23}$ Issues showing differences of $+/-4$ and 5 revised categories were deleted from the sample because there were few in each class. A total of approximately forty observations were lost for this reason. 
higher by Standard and Poor's) is different from zero at the $10 \%$ level and inversely related to measured YOT.

F-tests on the subset of coefficients for the split categories indicate the coefficients are significantly different from zero, as a group. In addition, the positive split group is jointly different from the intercept term; the negative splits, indicating higher Standard and Poors ratings for particular issues, are not. Some of this difference may be due to the presence of more positive split observations in the later years of the sample. Of the six intra-group boundaries, only the coefficients for a positive three and a positive two split are significantly different from each other.

The rating classes are still significantly different from one another in Model 2. An F-test confirms that the same class relationships hold from Model 1B. Evidently, the basic relationship connecting splits, ratings and yields is not completely described by this specification. The model results suggest that split issues generally have higher yield spreads, but that this higher spread may be due to the impact of Moody's versus Standard and Poor's as the rater assigning the higher issue. In other words, split ratings may not be symmetric with respect to the rater which assigned the higher rating.

Table 5 contains the distribution of split magnitudes across the six broad classes of bond rating and each of the seven subclasses for each issue year. As noted above, Aaa bonds cannot have any negative split observations. Split magnitude and direction refer to the Standard and Poor's "revised" rating subtracted from the Moody's revised rating. Nineteen sub-categories (such as Aa1, Aa2 and Aa3 for Moody's and AA+, AA and AA- for Standard and Poor's) were initially developed from the data.

Model 3 was created to exploit the relationships evident in Table 5. This model adds interaction terms for split magnitudes and directions and specific ratings classes for those interactions which had thirty or more observations over the sample period. ${ }^{24}$ As shown in Table VI, the positive split coefficients lose most of their explanatory power compared with Model 2, though an F-test indicates that the positive split interaction estimates as a group are still different from zero at the 0.01 level. ${ }^{25}$ The positive three-split coefficient remains different from zero at the 0.05 level. The P1BAA coefficient is positively related to issue yield spread and different from zero, as would be expected from Model 2. Although only one of the Model 2 negative split terms is significant, when these observations are grouped by rating class the coefficients for N2BA, N1BA, and N1B are inversely related to YOT and significant at the 0.01 level. In addition, the coefficients of N1B and N1BA are different from the model intercept at the 0.01 level, and the P1BAA term is different from the intercept at the 0.10 level. None of the adjacent interactions were significantly different from each other.

\footnotetext{
24 The same model was estimated using all interactions terms having existing observations; the significance of the model coefficients and the model's overall explanatory power were no different.

${ }^{25}$ Coefficients found using all interactions which had observed values were not significantly different from zero as a group. This may be due to contextual outliers not identified before due to the limited information used by the original
} 
Table 4: Initial regression results

The model explains new security yield off-Treasury measured with an exact maturity match constant maturity Treasury rate. CMQSYLD is the difference between Moody's Aaa Corporate Bond Index and the matchedmaturity CM rate; LNGROSS is the natural log of the issue size (in millions); TERM is the term to maturity of the issue (in years); DMAD1WLG is the mean absolute deviation in the spread between Moody's Aaa index yield (weekly) and an index of long-term (10+ years) government bonds (weekly) for the 26 weeks prior to the issue date; SFDUM, CRFDUM, SECDUM, EURO and SPLIT are 0/1 dummy variables for the existence of a sinking fund, a known call or refund date, a secured issue, a euro issue, and a split between the ratings given the issue by Moody's and S\&P. AAACL through BCL are dummy variables for the general ratings class for the issue's Moody's rating, with A (1,280 obs.) being the omitted class. MDIFN3 through MDIFP3 are dummy variables for the magnitude and sign of the difference between the issue's Moody's rating and its Standard \& Poors rating, with 0 (no difference) being the omitted class. Model 1A was estimated before the elimination of 8 outlier observations, as indicated by values calculated by the INFLUENCE option in SAS PROC REG. Model 1B is identical to $1 \mathrm{~A}$ with this exception. All four models were significant at the 0.01 level. *** indicates individual coefficient significance at the 0.01 level; ** indicates significance at the 0.05 level, and * indicates significance at the 0.10 level.

\begin{tabular}{|c|c|c|c|}
\hline Regressor & Model 1A (w/ outliers) & Model 1B & Model 2 \\
\hline Intercept & $\begin{array}{c}-0.02817 \\
(0.10940)\end{array}$ & $\begin{array}{l}-0.00465 \\
(0.10316)\end{array}$ & $\begin{array}{c}-0.01685 \\
(0.10309)\end{array}$ \\
\hline CMQSYLD & $\begin{array}{c}0.17227 * * * \\
(0.02676)\end{array}$ & $\begin{array}{c}0.15008 * * * \\
(0.02530)\end{array}$ & $\begin{array}{c}0.15290 * * * \\
(0.02521)\end{array}$ \\
\hline LNGROSS & $\begin{array}{l}0.03412^{*} \\
(0.01779)\end{array}$ & $\begin{array}{c}0.03858 * * \\
(0.01676)\end{array}$ & $\begin{array}{c}0.04556 * * \\
(0.01679)\end{array}$ \\
\hline TERM & $\begin{array}{c}0.02177 * * * \\
(0.00182)\end{array}$ & $\begin{array}{c}0.02139 * * * \\
(0.00171)\end{array}$ & $\begin{array}{c}0.02118 * * * \\
(0.00170)\end{array}$ \\
\hline DMAD1WLG & $\begin{array}{c}1.47257 * * * \\
(0.30805)\end{array}$ & $\begin{array}{c}1.50049 * * * \\
(0.28991)\end{array}$ & $\begin{array}{c}1.45888 * * * \\
(0.28889)\end{array}$ \\
\hline SFDUM & $\begin{array}{c}0.07705 \\
(0.05920)\end{array}$ & $\begin{array}{c}0.07432 \\
(0.05568)\end{array}$ & $\begin{array}{c}0.07330 \\
(0.05544)\end{array}$ \\
\hline CRFDUM & $\begin{array}{l}0.06449 * \\
(0.03307)\end{array}$ & $\begin{array}{c}0.06915^{* *} \\
(0.03110)\end{array}$ & $\begin{array}{c}0.06636 * * \\
(0.03098)\end{array}$ \\
\hline SECDUM & $\begin{array}{c}0.00203 \\
(0.03614)\end{array}$ & $\begin{array}{l}-0.00105 \\
(0.03401)\end{array}$ & $\begin{array}{l}-0.02190 \\
(0.03417)\end{array}$ \\
\hline EURO & $\begin{array}{c}0.07547 \\
(0.07250)\end{array}$ & $\begin{array}{c}-0.14941 * * \\
(0.06945)\end{array}$ & $\begin{array}{c}-0.14740 * * \\
(0.06917)\end{array}$ \\
\hline SPLIT & $\begin{array}{c}0.04567 \\
(0.02889)\end{array}$ & $\begin{array}{l}0.03365 \\
(0.2720)\end{array}$ & \\
\hline AAACL & $\begin{array}{c}-0.21133 * * \\
(0.07574)\end{array}$ & $\begin{array}{c}-0.40039 * * * \\
(0.07211)\end{array}$ & $\begin{array}{c}-0.42812 * * * * \\
(0.07204)\end{array}$ \\
\hline AACL & $\begin{array}{c}-0.18943 * * * \\
(0.04129)\end{array}$ & $\begin{array}{c}-0.18186 * * * \\
(0.03887)\end{array}$ & $\begin{array}{c}-0.19303 * * * \\
(0.03888)\end{array}$ \\
\hline BAACL & $\begin{array}{c}0.49822 * * * \\
(0.03724)\end{array}$ & $\begin{array}{c}0.48291 * * * \\
(0.03505)\end{array}$ & $\begin{array}{c}0.47730 * * * \\
(0.03496)\end{array}$ \\
\hline BACL & $\begin{array}{c}2.15609 * * * \\
(0.06510)\end{array}$ & $\begin{array}{c}2.14868 * * * \\
(0.06123)\end{array}$ & $\begin{array}{c}2.14332 * * * \\
(0.06140)\end{array}$ \\
\hline $\mathrm{BCL}$ & $\begin{array}{c}3.82686 * * * \\
(0.05185)\end{array}$ & $\begin{array}{c}3.81258 * * * \\
(0.04877)\end{array}$ & $\begin{array}{c}3.78290 * * * \\
(0.04892)\end{array}$ \\
\hline MDIFN3 & & & $\begin{array}{l}-0.09849 \\
(0.11757)\end{array}$ \\
\hline MDIFN2 & & & $\begin{array}{l}-0.12102 * \\
(0.06236)\end{array}$ \\
\hline MDIFN1 & & & $\begin{array}{l}-0.05249 \\
(0.03667)\end{array}$ \\
\hline MDIFP1 & & & $\begin{array}{c}0.10159 * * \\
(0.03456)\end{array}$ \\
\hline MDIFP2 & & & $\begin{array}{c}0.13497 * * \\
(0.06011)\end{array}$ \\
\hline MDIFP3 & & & $\begin{array}{c}0.39338^{* *} \\
(0.12077)\end{array}$ \\
\hline R-square & 0.7017 & 0.7300 & 0.7327 \\
\hline Adj. R-square & 0.7004 & 0.7288 & 0.7311 \\
\hline Number of obs.: & 3,293 & 3,285 & 3,285 \\
\hline
\end{tabular}




\section{Table 5: Refined split model regression}

The model explains new security yield off-Treasury measured with an exact maturity match constant maturity Treasury rate. CMQSYLD is the difference between Moody's Aaa Corporate Bond Index and the matched-maturity CM rate; LNGROSS is the natural log of the issue size (in millions); TERM is the term to maturity of the issue (in years); DMAD1WLG is the mean absolute deviation in the spread between Moody's Aaa index yield (weekly) and an index of long-term (10+ years) government bonds (weekly) for the 26 weeks prior to the issue date; SFDUM, CRFDUM, SECDUM, and EURO are 0/1 dummy variables for the existence of a sinking fund, a known call or refund date, a secured issue, and a euro issue. AAACL through BCL are dummy variables for the general ratings class for the issue's Moody's rating, with A (1,280 obs.) being the omitted class. MDIFN3 through MDIFP3 are dummy variables for the magnitude and sign of the difference between the issue's Moody's rating and its Standard \& Poors rating, with 0 (no difference) being the omitted class. N1AA through P1B are interaction terms for the ratings class and the magnitude and sign of the split, for those categories which had more than 30 observations across the full sample period. The overall model is significant at the 0.01 level. $* * *$ indicates individual coefficient significance at the 0.01 level; ** indicates significance at the 0.05 level; * indicates significance at the 0.10 level.

\begin{tabular}{|c|c|c|c|}
\hline Regressor & Model 3 & Regressor & Model 3 \\
\hline Intercept & $\begin{array}{l}-0.01968 \\
(0.10388)\end{array}$ & N1AA & $\begin{array}{c}0.03493 \\
(0.09896)\end{array}$ \\
\hline CMQSYLD & $\begin{array}{c}0.15494 * * * \\
(0.02512)\end{array}$ & P1AA & $\begin{array}{c}0.08257 \\
(0.09362)\end{array}$ \\
\hline LNGROSS & $\begin{array}{c}0.04349 * * \\
(0.01674)\end{array}$ & N1BAA & $\begin{array}{l}-0.04814 \\
(0.08976)\end{array}$ \\
\hline TERM & $\begin{array}{c}0.02167 * * * \\
(0.00170)\end{array}$ & P1BAA & $\begin{array}{c}0.19301 * * \\
(0.08787)\end{array}$ \\
\hline DMAD1WLG & $\begin{array}{c}1.42844 * * * \\
(0.28798)\end{array}$ & P2BAA & $\begin{array}{c}0.05189 \\
(0.15058)\end{array}$ \\
\hline SFDUM & $\begin{array}{c}0.06345 \\
(0.05527)\end{array}$ & N2BA & $\begin{array}{c}-0.73332 * * * \\
(0.17900)\end{array}$ \\
\hline CRFDUM & $\begin{array}{l}0.06113 * * \\
(0.03088)\end{array}$ & N1BA & $\begin{array}{c}-0.65103 * * * \\
(0.17081)\end{array}$ \\
\hline SECDUM & $\begin{array}{l}-0.01057 \\
(0.03414)\end{array}$ & P1BA & $\begin{array}{c}-0.14259 \\
(0.17135)\end{array}$ \\
\hline EURO & $\begin{array}{c}-0.14894 * * \\
(0.06892)\end{array}$ & $\mathrm{P} 2 \mathrm{BA}$ & $\begin{array}{l}-0.10888 \\
(0.19505)\end{array}$ \\
\hline AAACL & $\begin{array}{c}-0.40939 * * * \\
(0.07237)\end{array}$ & N1B & $\begin{array}{c}-0.51393 * * * \\
(0.13227)\end{array}$ \\
\hline AACL & $\begin{array}{c}-0.21150 * * * \\
(0.05043)\end{array}$ & P1B & $\begin{array}{c}0.11469 \\
(0.10225)\end{array}$ \\
\hline BAACL & $\begin{array}{c}0.44811 * * * \\
(0.04731)\end{array}$ & & \\
\hline BACL & $\begin{array}{c}2.24283 * * * \\
(0.10176)\end{array}$ & & \\
\hline BCL & $\begin{array}{c}3.84057 * * * \\
(0.06259)\end{array}$ & & \\
\hline MDIFN3 & $\begin{array}{l}-0.13238 \\
(0.11740)\end{array}$ & & \\
\hline MDIFN2 & $\begin{array}{l}-0.03094 \\
(0.06765)\end{array}$ & & \\
\hline MDIFN1 & $\begin{array}{c}0.02295 \\
(0.05357)\end{array}$ & & \\
\hline MDIFP1 & $\begin{array}{c}0.02279 \\
(0.05409)\end{array}$ & & \\
\hline MDIFP2 & $\begin{array}{c}0.10451 \\
(0.07256)\end{array}$ & & \\
\hline MDIFP3 & $\begin{array}{c}0.36138 * * \\
(0.12038)\end{array}$ & & \\
\hline
\end{tabular}


The main conclusion implied by the Model 3 results is that additional information provided by the general rating classes in conjunction with the magnitude and direction of a rating split adds to the overall explanatory power of the model, given an adequate number of issues for each interaction tested. In general, the results of Model 3 suggest that the relationship between splits, new issue yield spreads and the more highly rating agency may depend on the direction and size of the split as well as the broad rating class assigned to the security. Separately, the impact of splits appears to be smaller for lower credit rating classes, consistent with the idea that default risk is not priced in equal intervals across rating classes.

\section{Conclusion}

This study presents evidence confirming new findings: (1) the ability of credit ratings to explain differing yield spreads on new issues; (2) the higher yield premiums are paid by issues with split ratings; and (3) the need to recognize the interactions between ratings and split magnitude and direction in any model of new issue yields off-Treasury. Several of the results also suggest that the relationship between spreads and split ratings may not be symmetric across issues rated higher by Standard and Poor's and those rated higher by Moody's.

The data set developed for this study is more comprehensive in the number of issues and issue dates than data used in prior research on these questions. A natural extension of this work would involve reducing the potential firm, industry and time-series effects that remain uncorrected in the data.

Author statement: Timothy B. Michael is a professor in the School of Business, University of Houston, Clear Lake. He may be reached at michael@uhcl.edu. He wishes to record his appreciation to the journal editors for the review of this article and also their editing of the article to incorporate the changes. The responsibility for remaining errors rests with the author.

\section{References}

Billingsley, Randall S., Robert E. Lamy, M. Wayne Marr, and G. Rodney Thompson. (1985). Split ratings and bond reoffering yields. Financial Management 14(2): 59 - 65.

Brigham, Eugene F. and Louis C. Gapenski (1994). Financial Management: Theory and Practice. Fort Worth, Texas, Dryden Press.

Ederington, Louis H., Jess B. Yawitz and Brian E. Roberts (1987). The informational content of bond ratings. Journal of Financial Research 10(3): $211-226$.

Freund, Rudolf J. and Ramon C. Littell (1991). SAS System for Regression, Second Edition. Cary, North Carolina, SAS Institute, Inc.

Greene, William H. (1993). Econometric Analysis, Second Edition. Englewood Cliffs, New Jersey, Prentice-Hall. 
Guedes, Jose and Tim Opler (1995). The determinants of the maturity of corporate debt issues. Working Paper: Ohio State University.

Hsueh, L. Paul and P.R. Chandy (1989). An examination of the yield spread between insured and uninsured issues. Journal of Financial Research 12(3): 235 - 244.

Kao, Chihwa and Chunchi Wa (1994). A re-examination of the impact of credit ratings and economic factors on state bond yields. Review of Quantitative Finance and Accounting 4: 59 - 78.

Kaplan, Robert S. and Gabriel Urwitz (1979). Statistical models of bond ratings: a methodological inquiry. Journal of Business 52(2): 231 - 261.

Kennedy, Peter (1992). A Guide to Econometrics, Third Edition. Cambridge, Massachusetts, MIT Press.

Kidwell, David S., M. Wayne Marr and G. Rodney Thompson (1984). SEC rule 415: the ultimate competitive bid. Journal of Financial and Quantitative Analysis 19(2): 183 - 195.

Kidwell, David S., M. Wayne Marr, and Joseph P. Ogden (1989). The effect of a sinking fund on the reoffering yields of new public utility bonds. Journal of Financial Research 12(1), 1 - 13.

Liu, Pu and William T. Moore (1987). The impact of split bond ratings on risk premia. Financial Review 22(1): 71 - 85.

Liu, Pu and Anjan V. Thakor (1984). Interest yields, credit ratings, and economic characteristics of state bonds: an empirical analysis. Journal of Money, Credit, and Banking 16(3): 344 - 350.

Perry, Larry G., Pu Liu and Dorla A. Evans (1988). Modified bond ratings: Further evidence on the effect of split ratings on corporate bond yields. Journal of Business Finance \& Accounting 15(2): 231 - 241.

Pindyck, Robert S. and Daniel L. Rubinfeld (1981). Econometric Models and Econometric Forecasts, Second Edition. U.S.A.: McGraw-Hill.

Reiter, Sara A. and David A. Ziebart (1991). Bond yields, ratings, and financial information: evidence from public utility issues. The Financial Review 26(1): $45-73$.

SAS Institute, Inc. (1989). SAS/STAT User's Guide, Version 6, Volume 2. Cary, North Carolina, SAS Institute, Inc.

Sorensen, Eric H. (1979). The impact of underwriting method and bidder competition upon corporate bond interest cost. The Journal of Finance 34(4): 863 - 870.

Sorensen, Eric H. (1982). On the seasoning process of new bonds: Some are more seasoned than others. Journal of Financial and Quantitative Analysis 17(2): 195 - 208.

Zivney, Terry L., William J. Bertin and Khalil M. Torabzadeh (1993). A reexamination of the investment performance of junk bonds. Quarterly Journal of Business and Economics 32(2), 78 - 97. 


\section{Appendix: Moody's Ratings vs. Standard \& Poor's Ratings by Year of Issue}

Securities are listed under the column corresponding to the rating given by Moody's. For example, the "1" under Aaa, column P2 is an issue rated one subclass category higher by Moody's (Aaa) than by Standard and Poors (AA+)

Panel A: Aaa, Aa, and A Ratings

\begin{tabular}{|c|c|c|c|c|c|c|c|c|c|c|c|c|c|c|c|c|c|c|}
\hline & Aaa & & & & & & & $\overline{\mathbf{A a}}$ & & & & & & & $\overline{\mathbf{A}}$ & & & \\
\hline Year & & $\mathrm{P} 1$ & P2 & P3 & N3 & $\mathrm{N} 2$ & N1 & & $\mathrm{P} 1$ & $\mathrm{P} 2$ & P3 & N3 & $\mathrm{N} 2$ & N1 & & $\mathrm{P} 1$ & $\mathrm{P} 2$ & P3 \\
\hline 1983 & 2 & 2 & 1 & & & 1 & 6 & 15 & 4 & & & & 2 & 8 & 16 & 12 & 3 & 1 \\
\hline 1984 & & & & & & & 5 & 10 & & & & 1 & 5 & 12 & 12 & 12 & 4 & \\
\hline 1985 & 8 & 3 & 1 & & & 1 & 9 & 24 & 11 & & 1 & 2 & 6 & 22 & 49 & 19 & 8 & 3 \\
\hline 1986 & 12 & 4 & 3 & & & 1 & 18 & 55 & 19 & 2 & 3 & 5 & 11 & 48 & 78 & 30 & 17 & 2 \\
\hline 1987 & 6 & 1 & 3 & & & 2 & 9 & 27 & 12 & 1 & & 5 & 9 & 21 & 39 & 21 & 14 & 3 \\
\hline 1988 & 10 & 4 & & & & & 5 & 17 & 6 & & & 2 & 16 & 14 & 44 & 20 & 7 & \\
\hline 1989 & 13 & 1 & & & & 2 & 3 & 27 & 6 & 3 & & & 7 & 13 & 24 & 24 & 2 & 1 \\
\hline 1990 & 2 & & & & & & 1 & 22 & 6 & & & 1 & 4 & 17 & 41 & 18 & 1 & 1 \\
\hline 1991 & 16 & & & & & & 13 & 32 & 12 & & 1 & & 4 & 40 & 82 & 34 & 4 & 1 \\
\hline 1992 & 23 & 2 & & & & 3 & 22 & 48 & 25 & 7 & 6 & 6 & 11 & 55 & 81 & 38 & 9 & 1 \\
\hline 1993 & 10 & & & & & 1 & 14 & 29 & 31 & & & 1 & 14 & 44 & 60 & 30 & 6 & 2 \\
\hline $\begin{array}{c}\text { Column } \\
\text { Totals }\end{array}$ & 102 & 17 & 8 & 0 & 0 & 11 & 105 & 306 & 132 & 13 & 11 & 23 & 89 & 294 & 526 & 258 & 75 & 15 \\
\hline Class & & 127 & & & & & & 570 & & & & & & & 1280 & & & \\
\hline
\end{tabular}


Panel B: Baa, Ba, and B Ratings

\begin{tabular}{|c|c|c|c|c|c|c|c|c|c|c|c|c|c|c|c|c|c|c|c|c|c|c|}
\hline Year & N3 & $\mathrm{N} 2$ & N1 & Baa & $\mathrm{P} 1$ & $\mathrm{P} 2$ & P3 & N3 & $\mathrm{N} 2$ & N1 & $\mathbf{B a}$ & $\mathrm{P} 1$ & $\mathrm{P} 2$ & P3 & N3 & $\mathrm{N} 2$ & N1 & B & $\mathrm{P} 1$ & $\mathrm{P} 2$ & P3 & $\begin{array}{c}\text { Annual } \\
\text { Total }\end{array}$ \\
\hline 1983 & 1 & 1 & 10 & 18 & 11 & 2 & & & 1 & & 1 & 3 & 1 & & & & 2 & & 1 & & & 127 \\
\hline 1984 & & 2 & 10 & 10 & 7 & 3 & & & & 3 & 1 & 3 & & & & 2 & 1 & 9 & 2 & 1 & 1 & 116 \\
\hline 1985 & & 1 & 9 & 21 & 8 & 3 & & 1 & 6 & & & 4 & 4 & & & 1 & 4 & 7 & 8 & 6 & 1 & 251 \\
\hline 1986 & 3 & 6 & 25 & 19 & 34 & 5 & & 2 & 3 & 4 & 3 & 4 & 4 & 3 & 1 & 2 & 2 & 14 & 24 & 5 & 1 & 472 \\
\hline 1987 & & 2 & 12 & 34 & 19 & 1 & & & 4 & & 6 & 2 & 1 & & 5 & 5 & 4 & 14 & 16 & 2 & 2 & 302 \\
\hline 1988 & 1 & 1 & 7 & 25 & 13 & 3 & 3 & 2 & 2 & 1 & 2 & 3 & 3 & & 1 & 2 & 4 & 16 & 22 & 8 & 1 & 265 \\
\hline 1989 & & 3 & 4 & 23 & 5 & 4 & & & 3 & 3 & 3 & 2 & 2 & 1 & & 1 & 2 & 14 & 12 & 1 & 1 & 210 \\
\hline 1990 & & & 7 & 28 & 15 & 3 & & & 1 & & & & & & & & & & 1 & & & 169 \\
\hline 1991 & & & 8 & 43 & 14 & 2 & & & 1 & 2 & 5 & 2 & 1 & & & 2 & & 1 & 3 & & & 323 \\
\hline 1992 & 2 & 6 & 30 & 93 & 26 & 6 & & & 3 & 15 & 20 & 7 & 4 & & & & 16 & 46 & 15 & 15 & 1 & 627 \\
\hline 1993 & & 1 & 23 & 66 & 10 & 3 & 1 & 1 & 7 & 5 & 9 & 3 & 4 & 1 & & 2 & 12 & 21 & 13 & 1 & & 425 \\
\hline $\begin{array}{l}\text { Column } \\
\text { Totals }\end{array}$ & 7 & 23 & 145 & 380 & 162 & 35 & 4 & 6 & 31 & 33 & 50 & 33 & 24 & 5 & 7 & 17 & 47 & 142 & 117 & 25 & 7 & \\
\hline $\begin{array}{l}\text { Class } \\
\text { Totals }\end{array}$ & & & & 752 & & & & & & & 182 & & & & & & & 362 & & & & 3,287 \\
\hline
\end{tabular}

